\title{
Pressure-derived indices of left ventricular isovolumic relaxation in patients with hypertrophic cardiomyopathy
}

\author{
D S THOMPSON, P WILMSHURST, S M JUUL, C B WALDRON, B S JENKINS, \\ D J COLTART, M M WEBB-PEPLOE
}

From the Departments of Cardiology, Medicine, and Bioengineering, St Thomas's Hospital, London

SUMMARY High fidelity measurements of left ventricular pressure were made at increasing pacing rates in 21 patients with hypertrophic cardiomyopathy and a control group of 11 patients investigated for chest pain who proved to have normal hearts. In both groups the fall in pressure during isovolumic relaxation from the point of $\mathrm{min} \mathrm{dp} / \mathrm{dt}$ approximated closely to a monoexponential, and could be described by a time constant and asymptote.

The time constant shortened and the asymptote increased as heart rate rose in both groups. The time constant was longer and min dp/dt less in the cardiomyopathy group than controls at all heart rates. In the cardiomyopathy patients $\mathrm{min} \mathrm{dp} / \mathrm{dt}$, but not the time constant, was related to systolic pressure. During pacing, eight cardiomyopathy patients developed metabolic evidence of myocardial ischaemia, but indices of relaxation did not differ between these eight and the other 13 either at basal heart rate or the highest pacing rate.

In 10 cardiomyopathy patients measurements were repeated at comparable pacing rates after propranolol $(0.2 \mathrm{mg} / \mathrm{kg})$. Left ventricular end-diastolic pressure and indices of contractility decreased after the drug, but the time constant did not change. Eight patients received verapamil (20 $\mathrm{mg}$ ) after which there were substantial reductions in systolic pressure and contractility. Min dp/dt decreased in proportion to systolic pressure, but the time constant was unchanged. At the highest pacing rate before drug administration three patients had abnormal lactate extraction which was corrected by either propranolol (one patient) or verapamil (two patients). Despite abolition of metabolic evidence of ischaemia, relaxation did not improve.

It is concluded that abnormal isovolumic relaxation is common in patients with hypertrophic cardiomyopathy, but its severity correlates poorly with other features of the disease. Abnormal relaxation is not the result of ischaemia, and pressure derived indices of relaxation do not improve after the administration of propranolol or verapamil.

Impairment of left ventricular relaxation and diastolic function is common in patients with hypertrophic cardiomyopathy ${ }^{-5}$ and may reflect the severity and distribution of inappropriate hypertrophy 34 or be the result of myocardial ischaemia. ${ }^{15}$ Relaxation and diastolic function can improve after the administration of beta blocking drugs ${ }^{16}$ or verapamil. ${ }^{5}$ It is uncertain whether these drugs act directly upon the diseased myocardium ${ }^{5}$ or by relieving ischaemia. ${ }^{1}$

The physiology of ventricular relaxation is poorly understood ${ }^{7}$ and its study is limited by the lack of methods of quantifying isovolumic pressure fall. Min $\mathrm{dp} / \mathrm{dt}$ is measured easily, but describes only one point during relaxation, and because it depends upon systolic pressure ${ }^{8}$ is of little use in comparing patients or investigating drugs that change arterial pressure. The fall in left ventricular pressure from the point of min $\mathrm{dp} / \mathrm{dt}$ until mitral valve opening approximates to a monoexponential so that the rate of relaxation can be described by a time constant ${ }^{9-11}$ which, in contrast to $\min \mathrm{dp} / \mathrm{dt}$, characterises pressure fall throughout the majority of isovolumic relaxation, and is insensitive to systolic pressure. ${ }^{9}$ Unfortunately the usual method of estimating the time constant, from the slope of $\ln$ 
(pressure) against time, ${ }^{9-11}$ has serious deficiencies which have been discussed in detail elsewhere. ${ }^{12-14}$ An alternative method of exponential analysis has been developed and the model upon which it is based and the accuracy of its estimates of the time constant and asymptote of isovolumic pressure fall have been validated in patients with a variety of left ventricular disease. ${ }^{1314}$ In patients with coronary artery disease the time constant so derived is sensitive to myocardial ischaemia. ${ }^{13}$

We have applied this method to measurements of left ventricular pressure made in 21 patients with hypertrophic cardiomyopathy and a control group of 11 patients who proved to have normal hearts. Our purpose was to measure the severity of impaired relaxation in hypertrophic cardiomyopathy, investigate its relation to ischaemia, and to determine whether propranolol or verapamil could improve relaxation.

\section{Patients and methods}

Twenty one patients with hypertrophic cardiomyopathy were studied during diagnostic cardiac catheterisation. The control group consisted of 11 patients investigated for chest pain who proved to have normal hearts. Details of some of the patients in both groups have been reported previously. ${ }^{14} 15$

\section{CARDIAC CATHETERISATION}

The procedure was approved by the hospital's ethical committee. The catheter procedure has been described in detail elsewhere. ${ }^{15} 16$ Briefly, diagnostic catheterisation was performed via the right femoral vein and artery. In the cardiomyopathy patients the gradient was derived from simultaneous measurements of left ventricular body and outflow pressures. Where appropriate, amyl nitrate or an extrasystole was used to provoke a gradient. The left heart catheter was replaced by a micromanometer (either Telco MM52, Gaeltec No. 8, or Millar No. 5) via a long sheath. ${ }^{17}$ A Ganz catheter was positioned in the coronary sinus via a left arm vein. Left ventricular pressure was measured and coronary sinus and left ventricular blood sampled at basal heart rate and during incremental coronary sinus pacing. Measurements and samples were repeated at comparable pacing rates in $\mathbf{1 0}$ cardiomyopathy patients $\mathbf{2 0}$ minutes after propranolol $(0.2 \mathrm{mg} / \mathrm{kg}$ iv), and in eight cardiomyopathy patients seven minutes after verapamil $(20 \mathrm{mg})$. Ventricular cineangiography was performed at the end of the study.

MEASUREMENT OF LEFT VENTRICULAR PRESSURE The sternal angle was used as zero reference. Left ventricular pressure was measured simultaneously by the catheter tip micromanometer and the lumen of the catheter, or via the long sheath when a 5 Millar was used. The catheter laboratory computer digitised the micromanometer signal at $5 \mathrm{~ms}$ intervals and the lumen pressure every $10 \mathrm{~ms}$. As previously described, 흘 the lumen pressure was used to calibrate the mic- $\frac{}{7}$ romanometer for the analysis of each pressure $\stackrel{\mathbb{\complement}}{\stackrel{1}{\circ}}$ record. ${ }^{13} 14$

\section{ESTIMATION OF TIME CONSTANT}

In each beat the computer recognised the period of $\vec{\omega}$ isovolumic relaxation to be analysed as starting at the time of $\mathrm{min} \mathrm{dp} / \mathrm{dt}$ and ending when pressure decreased to the level of end-diastolic pressure of the $\frac{10}{6}$ preceding beat. 9111314 The analysis was based upon a $\omega$ monoexponential of which the time constant andin asymptote are variable. ${ }^{1314}$ Thus $P(t)=a e^{b t}+c^{0}$ where $P(t)=$ pressure at time $t, t=$ time in $m s$ after $ᄋ$ $\min \mathrm{dp} / \mathrm{dt}$, and $\mathrm{c}=$ the asymptote. The time constant $=-\frac{1}{b}$. In each beat, by analysing successive sets of $\frac{3}{d}$ three points on the digitised pressure-time curve, the computer calculated the time constant and asymptote. $\vec{T}$ This method of analysis has been described in detail $\mathscr{\odot}_{\infty}$ elsewhere. ${ }^{14}$

The computer also calculated systolic and enddiastolic pressures, $\max \mathrm{dp} / \mathrm{dt}$, $\mathrm{min} \mathrm{dp} / \mathrm{dt}$, and $\mathrm{KVmax}$ (from developed pressure ${ }^{18}$ ) for each beat. The values that appear in the results are the mean of all the beats in a nine second record.

\section{LACTATE CONCENTRATION}

Blood samples were added to an aliquot of perchloric $\supset$ acid, frozen, and subsequently analysed by a photofluorometric method. ${ }^{19}$ Extraction ratio is the difference between lactate concentrations in left ven- $\mathbb{D}$ tricular and coronary sinus blood expressed as a per-? centage of its concentration in left ventricular blood 3 $\left({ }^{\wedge-\mathrm{v}} / \mathrm{A} \%\right)$.

\section{STATISTICAL METHODS}

To test the validity of the exponential model the pres- $-\frac{}{2}$ sures predicted by the estimates of the time constant and asymptote were compared with measured pres-a. sure in 44 beats. The "goodness of fit" was assessed $N$ by the ratio of the residual to total sum of squares (RSS/TSS).

Elsewhere Student's $t$ test and linear regression ${ }^{\omega}$ were used. Values are expressed at mean \pm SEM. $p$ 0.05 is considered significant.

\section{Results}

The details of the patients with hypertrophic car $\frac{\overrightarrow{\mathrm{O}}}{\mathrm{D}}$ diomyopathy are listed in Table 1 . Each had clinical $\frac{?}{\mathrm{D}}$ electrocardiographic, and angiographic evidence of 0 left ventricular hypertrophy. Sixteen patients hade 
Table 1 Details of patients with hypertrophic cardiomyopathy

\begin{tabular}{|c|c|c|c|c|c|}
\hline $\begin{array}{l}\text { Case } \\
\text { No. }\end{array}$ & $\begin{array}{l}\text { Age } \\
(y)\end{array}$ & Sex & $\begin{array}{l}\text { Resting } \\
\text { gradient } \\
\text { (mmHg) }\end{array}$ & $\begin{array}{l}\text { Basal } \\
\text { lactate } \\
(\%)\end{array}$ & $\begin{array}{l}\text { Lactate extraction } \\
\text { ratio at highest } \\
\text { pacing rate }(\%)\end{array}$ \\
\hline $\begin{array}{r}1 \\
2 \\
3 \\
4 \\
5 \\
6 \\
7 \\
8 \\
9 \\
10 \\
11 \\
12 \\
13 \\
14 \\
15 \\
16 \\
17 \\
18 \\
19 \\
20 \\
21\end{array}$ & $\begin{array}{l}23 \\
43 \\
53 \\
42 \\
39 \\
58 \\
24 \\
41 \\
26 \\
29 \\
47 \\
33 \\
49 \\
60 \\
18 \\
28 \\
22 \\
17 \\
28 \\
57 \\
46\end{array}$ & $\begin{array}{l}F \\
F \\
F \\
M \\
M \\
M \\
M \\
M \\
M \\
F \\
M \\
M \\
M \\
F \\
F \\
M \\
F \\
M \\
F \\
M \\
M\end{array}$ & $\begin{array}{r}61 \\
36 \\
100 \\
49 \\
5 \\
26 \\
70 \\
27 \\
22 \\
69 \\
41 \\
14 \\
9 \\
3 \dagger \\
27 \\
0 \ddagger \\
0^{\star} \\
0^{\star} \\
0^{\star} \\
0^{\star} \\
0^{\star}\end{array}$ & $\begin{array}{r}44 \\
59 \\
25 \\
36 \\
20 \\
38 \\
56 \\
57 \\
35 \\
38 \\
36 \\
36 \\
15 \\
39 \\
26 \\
17 \\
18 \\
35 \\
36 \\
8 \\
55\end{array}$ & $\begin{array}{r}3 \\
-16 \\
-11 \\
45 \\
19 \\
25 \\
30 \\
29 \\
21 \\
3 \\
18 \\
21 \\
29 \\
34 \\
-19 \\
-33 \\
3 \\
18 \\
11 \\
-15 \\
44\end{array}$ \\
\hline
\end{tabular}

* Gradient not provoked by amyl nitrate or postextrasystole.

tGradient 53 during amyl nitrate inhalation.

$\$$ Gradient 15 during amyl nitrate inhalation.

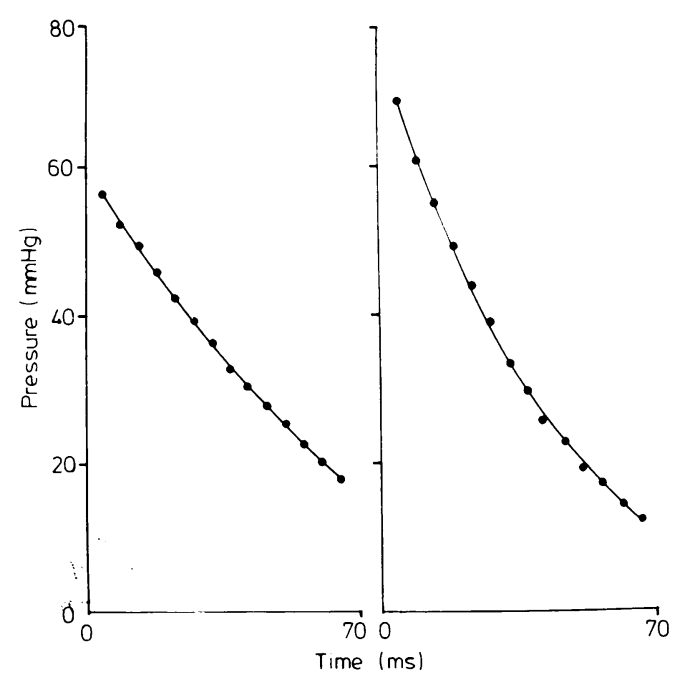

Fig. 1 Comparison of measured pressure with pressures predicted by the estimates of the time constant and asymptote. - measured pressure digitised at $5 \mathrm{~ms}$ intervals. Solid line: pressures predicted by exponential model. Left hand panel: a beat recorded at basal heart rate in a patient with hypertrophic cardiomyopathy. The time constant $=129 \mathrm{~ms}$ and the asymptote $-41 \mathrm{mmHg}$. When measured and predicted pressures are compared RSS $/ T S S=0 \cdot 2 \%$. Right hand panel: a beat recorded at basal heart rate in one of the controls. The time constant $=55 \mathrm{~ms}$, and the asymptote $-14 \mathrm{mmHg}$. RSS $/ T S S=0.2 \%$. outflow obstruction either at rest (15) or after amyl nitrate inhalation (one). In five patients a gradient could not be provoked by amyl nitrate or an extrasystole. Nineteen of the 21 had normal selective coronary arteriograms; one patient (case 13) had minor disease, and in the remaining patient normal proximal coronary arteries were demonstrated by aortography (case 15).

The 11 control subjects each had normal coronary arteriograms and did not develop pain or electrocardiographic abnormalities during pacing. Lactate concentrations were measured in nine. Myocardial lactate production was not observed and the lactate extraction ratio did not change significantly between basal heart rate and the highest pacing rate $(28 \% \pm 4$ to $23 \% \pm 4)$.

The pressures predicted by the estimate of the time constant and asymptote were compared with measured pressure in 32 beats recorded in eight patients with cardiomyopathy, and 12 beats from six normal subjects. Two examples are illustrated in Fig. 1. The beats analysed included examples at different pacing rates, and in the cardiomyopathy group beats recorded before and after drug administration. For beats from the cardiomyopathy group RSS/TSS ranged from $0.1 \%$ to $1.9 \%$; in 25 it was less than $0.5 \%$, and in five between $0.5 \%$ and $1 \%$. For the controls RSS/TSS ranged from $0 \cdot 1 \%$ to $0.8 \%$; in six it was less than $0.5 \%$.

Table 2 lists the haemodynamics in both groups at basal heart rate and the highest pacing rate. Min dp/dt was lower and the time constant longer in the car- 
Table 2 Comparison of hypertrophic cardiomyopathy group with controls: values expressed as mean $\pm S E M$

\begin{tabular}{|c|c|c|c|c|c|c|c|c|}
\hline & $\begin{array}{l}\text { Heart rate } \\
(b p m)\end{array}$ & $\begin{array}{l}\text { LVSP } \\
(m m H g)\end{array}$ & $\begin{array}{l}\text { LVEDP } \\
(\mathrm{mmHg})\end{array}$ & $K V \max / s$ & $\begin{array}{l}\operatorname{Max} d p / d t \\
(m m H g / s)\end{array}$ & $\begin{array}{l}\operatorname{Min} d p / d t \\
(m m H g / s)\end{array}$ & $\begin{array}{l}T \\
(m s)\end{array}$ & $\begin{array}{l}\text { Asymptote } \\
\text { (mmHg) }\end{array}$ \\
\hline \multirow{4}{*}{$\begin{array}{l}\text { Basal heart rate } \\
\text { HCM } \\
(\mathrm{n}=21) \\
\text { Controls } \\
(\mathrm{n}=11) \\
\text { Highest pacing rate } \\
\text { HCM } \\
(\mathrm{n}=21) \\
\text { Controls } \\
(\mathrm{n}=11)\end{array}$} & $82 \pm 3$ & $118 \pm 6$ & $12 \pm 1$ & $85 \pm 4$ & $1260 \pm 92$ & $-1078 \pm 66$ & $77 \pm 6$ & $-27 \pm 4$ \\
\hline & $90 \pm 6$ & $121 \pm 5$ & $\begin{array}{c}6 \pm 2 \\
p<0.001\end{array}$ & $93 \pm 4$ & $\begin{array}{l}1594 \pm 65 \\
p<0.005\end{array}$ & $\begin{array}{l}-1863 \pm 75 \\
p<0.001\end{array}$ & $\begin{array}{l}52 \pm 4 \\
p<0.001\end{array}$ & $-22 \pm 3$ \\
\hline & $137 \pm 4$ & $104 \pm 4$ & $12 \pm 2$ & $90 \pm 6$ & $1350 \pm 85$ & $-934 \pm 71$ & $57 \pm 5$ & $-10 \pm 3$ \\
\hline & $147 \pm 7$ & $118 \pm 6$ & $\begin{array}{c}1 \pm 1 \\
\mathrm{p}<0.001\end{array}$ & $106 \pm 6$ & $\begin{array}{l}2096 \pm 91 \\
\mathrm{p}<0.001\end{array}$ & $\begin{array}{l}-2025 \pm 100 \\
\mathrm{p}<0.001\end{array}$ & $\begin{array}{l}32 \pm 2 \\
p<0.001\end{array}$ & $-8 \pm 2$ \\
\hline
\end{tabular}

LVSP, left ventricular systolic pressure; LVEDP, left ventricular end-diastolic pressure; Max dp/dt, maximum rate of rise of LV pressure; Min dp/dt, minimum rate of fall of LV pressure; T, time constant of LV pressure fall.

Table 3 Comparison of patients with and without obstruction

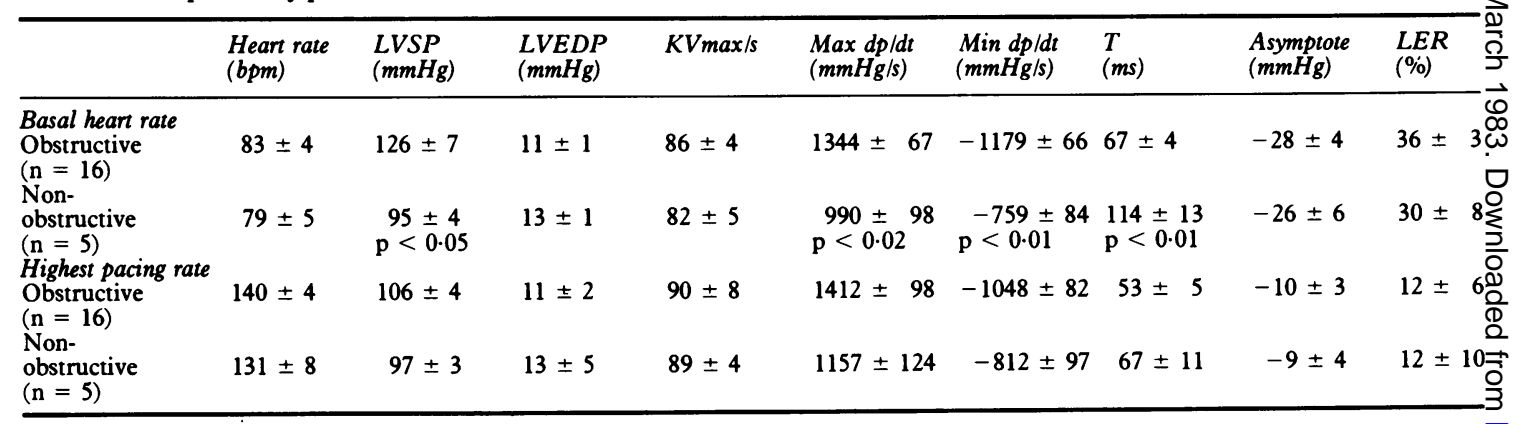

LER, lactate extraction ratio. Other abbreviations as in Table 2.

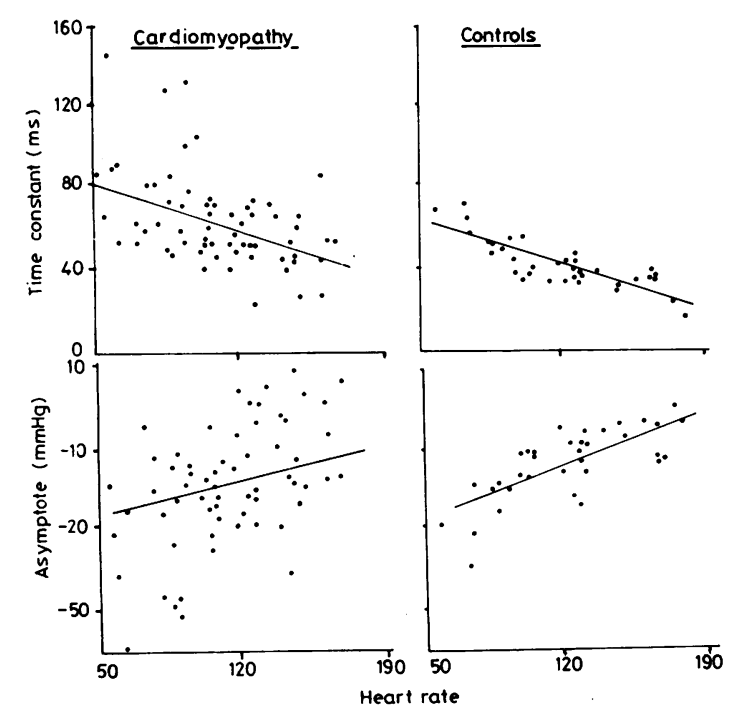

Fig. 2 Upper panels: the individual values of the time constants have been plotted against heart rate in the 21 patients with cardiomyopathy (left) and the 11 controls (right). In both groups $N$ the time constant shortened as heart rate increased: for the cardiomyopathy group $r=-0.42, p<0.001$, and for the controls $r=-0.83, p<0.001$. Lower panels: individual values of the asymptote in the cardiomyopathy patients (lefi) and controls (right) plotted against heart rate. For the cardiomyopathy patients $r=0.25, p<0.05$, and for the controf group $r=0.70, p<0.01$. 

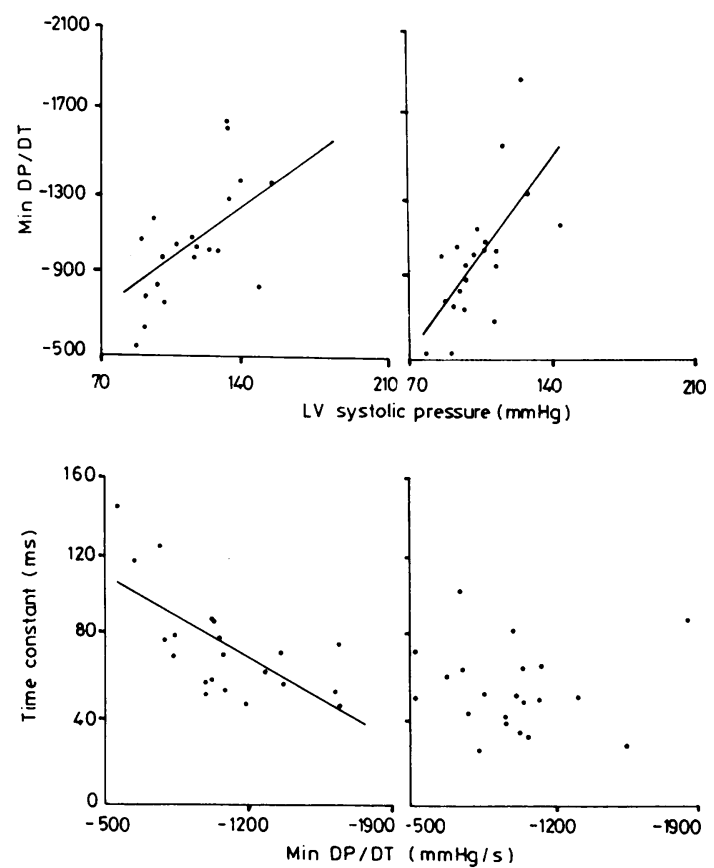

Fig. 3 Upper panels. The relation between min dp/dt and left ventricular systolic pressure in the 21 cardiomyopathy patients at basal heart rate (left) and the highest pacing rate (right). At basal heant rate $r=0.68, p<0.01$, and at the highest pacing rate $r=$ $0.67, p<0.01$. Lower panels: the time constant has been plotted against min dp/dt in the 21 cardiomyopathy patients at basal heart rate (left) and the highest pacing rate (right). At basal heart rate $r=-0.67, p<0.01$. The significance of the correlation is largely the result of the three patients who have the worst values of both indices of relaxation. At the highest heart rate the time constant and min dp/dt were not related significantly.

diomyopathy group compared with controls at both heart rates. In both groups the time constant shortened and the asymptote increased between basal heart rate and the highest pacing rate. When all heart rates were considered the time constant was related inversely and the asymptote positively to heart rate
(Fig. 2) in both groups. Min dp/dt increased with heart rate only in the controls. End-diastolic pressure was greater and $\max \mathrm{dp} / \mathrm{dt}$ lower in the cardiomyopathy patients compared with controls at both basal heart rate and the highest pacing rate. $\mathrm{KVmax}$ and max $\mathrm{dp} / \mathrm{dt}$ increased, and end-diastolic pressure decreased with pacing in the controls but not in the cardiomyopathy group.

In the cardiomyopathy patients there was wide variation in the indices of relaxation. Only at basal heart rate was there correlation between $\mathrm{min} \mathrm{dp} / \mathrm{dt}$ and the time constant (Fig. 3). Min dp/dt was related to systolic pressure at both heart rates (Fig. 3), but the time constant was not related to pressure, or to indices of contractility. At basal heart rate the time constant was longer and $\mathrm{min} \mathrm{dp} / \mathrm{dt}$ lower in the patients without obstruction (Table 3), but in the patients with obstruction the time constant could not be related to the gradient.

In the cardiomyopathy patients at basal heart rate myocardial lactate extraction ratio was $35 \% \pm 3$, and was greater than $10 \%$ in all but one (Table 1). At the highest pacing rate extraction ratio decreased to $12 \%$ \pm 5 . This reduction was largely because of eight patients who produced lactate or had extraction ratio of $<5 \%$ during pacing (Table 1 ). The haemodynamics of these eight and the other 13 are compared in Table 4. No differences were found between these two subgroups. In particular the indices of relaxation were comparable.

Measurements were repeated after propranolol in 10 cardiomyopathy patients (Table 5). At the lowest heart rate max dp/dt decreased after the drug, but the indices of relaxation did not change. At the highest pacing rate after the drug there were significant reductions in systolic and end-diastolic pressure, $\max \mathrm{dp} /$ $\mathrm{dt}, \mathrm{KVmax}$, and $\mathrm{min} \mathrm{dp} / \mathrm{dt}$, but the time constant was unchanged. Before the drug four of the 10 patients developed low or negative lactate extraction ratios during pacing. After the drug, extraction ratio improved substantially in only one patient, from $2.7 \%$ to $44 \%$. This was not accompanied by major improvement in relaxation; min $\mathrm{dp} / \mathrm{dt}$ decreased from

Table 4 Comparison of patients with nomal and abnormal lactate extraction

\begin{tabular}{|c|c|c|c|c|c|c|c|c|c|}
\hline & $\begin{array}{l}\text { Heart rate } \\
(\mathrm{bpm})\end{array}$ & $\begin{array}{l}L V S P \\
(m m H g)\end{array}$ & $\begin{array}{l}\text { LVEDP } \\
(m m H g)\end{array}$ & $K V \max / s$ & $\begin{array}{l}\operatorname{Max} d p / d t \\
(\operatorname{mmHg} / s)\end{array}$ & $\begin{array}{l}\operatorname{Min} d p / d t \\
(m m H g / s)\end{array}$ & $\begin{array}{l}T \\
(m s)\end{array}$ & $\begin{array}{l}\text { Asymptote } \\
\text { (mmHg) }\end{array}$ & $\begin{array}{l}\text { LER } \\
(\%)\end{array}$ \\
\hline $\begin{array}{l}\text { Basal heart rate } \\
\text { Normal }\end{array}$ & $81 \pm 4$ & $119 \pm 6$ & $11 \pm 1$ & $83 \pm 4$ & $1235 \pm 69$ & $-1062 \pm 79$ & $79 \pm 8$ & $-28 \pm 5$ & $36 \pm 3$ \\
\hline $\begin{array}{l}(\mathrm{n}=13) \\
\text { Abnormal } \\
(\mathrm{n}=8) \\
\text { Highest pacing ra }\end{array}$ & $85 \pm 6$ & $118 \pm 6$ & $13 \pm 3$ & $88 \pm 7$ & $1308 \pm 145$ & $-1107 \pm 141$ & $75 \pm 9$ & $-26 \pm 7$ & $30 \pm 8$ \\
\hline $\begin{array}{l}\text { Normal } \\
\text { Abnormal }\end{array}$ & $\begin{array}{l}132 \pm 4 \\
147 \pm 6\end{array}$ & $\begin{array}{r}107 \pm 5 \\
97 \pm 4\end{array}$ & $\begin{array}{l}12 \pm 3 \\
11 \pm 2\end{array}$ & $\begin{array}{l}89 \pm 5 \\
91 \pm 15\end{array}$ & $\begin{array}{l}1394 \pm 128 \\
1286 \pm 67\end{array}$ & $\begin{array}{r}-1013 \pm 110 \\
-958 \pm 49\end{array}$ & $\begin{array}{l}57 \pm 6 \\
58 \pm 7\end{array}$ & $\begin{array}{l}-10 \pm 4 \\
-10 \pm 3\end{array}$ & $\begin{array}{r}26 \pm 3 \\
-11 \pm 5 \\
\mathrm{p}<0.00\end{array}$ \\
\hline
\end{tabular}

Abbreviations as in Tables 2 and 3. 
Table 5 Effects of propranolol

\begin{tabular}{|c|c|c|c|c|c|c|c|c|}
\hline & $\begin{array}{l}\text { Heart rate } \\
(\text { bpm) }\end{array}$ & $\begin{array}{l}L V S P \\
(m m H g)\end{array}$ & $\begin{array}{l}\text { LVEDP } \\
(m m H g)\end{array}$ & $K V \max / s$ & $\begin{array}{l}\operatorname{Max} d p / d t \\
(m m H g / s)\end{array}$ & $\begin{array}{l}\text { Min dp/dt } \\
(m m H g / s)\end{array}$ & $\begin{array}{l}T \\
(m s)\end{array}$ & $\begin{array}{l}\text { Asymptote } \\
(\mathrm{mmHg})\end{array}$ \\
\hline \multicolumn{9}{|l|}{ Lowest pacing rate } \\
\hline $\begin{array}{l}\text { Before propranolol } \\
(n=10)\end{array}$ & $86 \pm 5$ & $126 \pm 11$ & $11 \pm 1$ & $87 \pm 6$ & $1437 \pm 86$ & $-1206 \pm 83$ & $69 \pm 6$ & $-32 \pm 5$ \\
\hline $\begin{array}{l}\text { After propranolol } \\
(\mathrm{n}=10) \\
\text { Highest pacing rate } \\
\text { Before }\end{array}$ & $89 \pm 5$ & $119 \pm 9$ & $8 \pm 2$ & $78 \pm 6$ & $\begin{array}{l}1160 \pm 148 \\
p<0.05\end{array}$ & $-1139 \pm 89$ & $62 \pm 3$ & $-22 \pm 5$ \\
\hline $\begin{array}{l}\text { propranolol } \\
(\mathrm{n}=10) \\
\text { After }\end{array}$ & $132 \pm 7$ & $121 \pm 9$ & $13 \pm 1$ & $101 \pm 7$ & $1540 \pm 99$ & $-1160 \pm 87$ & $54 \pm 5$ & $-15 \pm 4$ \\
\hline $\begin{array}{l}\text { propranolol } \\
(\mathrm{n}=10)\end{array}$ & $132 \pm 7$ & $\begin{array}{l}106 \pm 6 \\
p<0.02\end{array}$ & $\begin{array}{c}8 \pm 1 \\
p<0.01\end{array}$ & $\begin{array}{l}82 \pm 6 \\
p<0.05\end{array}$ & $\begin{array}{l}1301 \pm 72 \\
p<0.01\end{array}$ & $\begin{array}{l}-1009 \pm 73 \\
\mathrm{p}<0.02\end{array}$ & $55 \pm 4$ & $-14 \pm 5$ \\
\hline
\end{tabular}

Table 6 Effects of verapamil

\begin{tabular}{|c|c|c|c|c|c|c|c|c|}
\hline & $\begin{array}{l}\text { Heart rate } \\
\text { (bpm) }\end{array}$ & $\begin{array}{l}L V S P \\
(m m H g)\end{array}$ & $\begin{array}{l}L V E D P \\
(m m H g)\end{array}$ & $K V \max / s$ & $\begin{array}{l}\operatorname{Max} d p / d t \\
(m m H g / s)\end{array}$ & $\begin{array}{l}\text { Min } d p / d t \\
(m m H g / s)\end{array}$ & $\begin{array}{l}T \\
(m s)\end{array}$ & $\begin{array}{l}\text { Asymptote } \\
(\mathrm{mmHg})\end{array}$ \\
\hline \multirow{5}{*}{$\begin{array}{l}\text { Lowest pacing rate } \\
\text { Before verapamil } \\
(\mathrm{n}=8) \\
\text { After verapamil } \\
(\mathrm{n}=8) \\
\text { Highest pacing rate } \\
\text { Before verapamil } \\
(\mathrm{n}=7) \\
\text { After verapamil } \\
(\mathrm{n}=7)\end{array}$} & & & & & & & & \\
\hline & $86 \pm 7$ & $115 \pm 10$ & $12 \pm 2$ & $82 \pm 4$ & $1104 \pm 48$ & $-905 \pm 87$ & $90 \pm 13$ & $-26 \pm 5$ \\
\hline & $85 \pm 7$ & $p< \pm 0.6$ & $10 \pm 3$ & $\begin{array}{l}69 \pm 5 \\
p<0.05\end{array}$ & $\begin{array}{c}902 \pm 60 \\
p<0.005\end{array}$ & $\begin{array}{l}-767 \pm 64 \\
p<0.005\end{array}$ & $93 \pm 12$ & $-24 \pm 4$ \\
\hline & $119 \pm 7$ & $114 \pm 9$ & $10 \pm 2$ & $82 \pm 4$ & $1262 \pm 117$ & $-957 \pm 101$ & $65 \pm 4$ & $-16 \pm 6$ \\
\hline & $113 \pm 7$ & $\begin{array}{r}96 \pm 6 \\
p<0.01\end{array}$ & $7 \pm 2$ & $\begin{array}{l}70 \pm 2 \\
p<0.02\end{array}$ & $\underset{p}{943 \pm 0.01} 55$ & $\begin{array}{l}-795 \pm 70 \\
\mathrm{p}<0.01\end{array}$ & $65 \pm 7$ & $-12 \pm 3$ \\
\hline
\end{tabular}

Abbreviations as in Table 2.

-1448 to $-1037 \mathrm{mmHg} / \mathrm{s}$, and the time constant from 65 to $58 \mathrm{~ms}$.

Measurements were repeated after verapamil in eight cardiomyopathy patients at the lowest heart rate and in seven at the highest pacing rate (Table 6). After the drug at both heart rates there were significant reductions in systolic pressure, $\mathrm{KVmax}, \max \mathrm{dp} / \mathrm{dt}$, and $\mathrm{min} \mathrm{dp} / \mathrm{dt}$, but no change in the time constant. Before verapamil two patients had low or negative lactate extraction ratios at the highest pacing rate $(3 \%$ and $-15 \%)$ which increased after the drug $(38 \%$ and $11 \%)$. Despite increased lactate extraction, indices of relaxation did not improve after the drug: $\min \mathrm{dp} / \mathrm{dt}$ decreased from -560 to $-501 \mathrm{mmHg} / \mathrm{s}$ and from -1046 to $-837 \mathrm{mmHg} / \mathrm{s}$, but the time constant was unchanged; 61 and $59 \mathrm{~ms}$, and 60 and $59 \mathrm{~ms}$.

\section{Discussion}

Our method of estimating the time constant, and the model upon which it is based, have been validated in patients with a variety of left ventricular disease. ${ }^{13} 14$ In the 44 beats tested in this study the pressures predicted by the estimates of the time constant and asymptote were in close agreement with measured pressure. It is legitimate, therefore, to describe isovolumic relaxation by a time constant estimated in this way.
Although left ventricular pressure fall during isovolumic relaxation approximates to a monoexponential in a wide range of circumstances, ${ }^{14}$ relaxation of isolated muscle is not characterised by exponential tension decay ${ }^{720}$ even when the relaxation sequence of the intact ventricle is imitated. ${ }^{721}$ This difference between isolated muscle and the left ventricle might be the result of the difficulty of simulating the complex load system of the heart, ventricular geometry, internal and external restoring forces operating upon the ventricular myocardium, ${ }^{22}{ }^{23}$ regional variation in the time of onset of relaxation, or the effect of coronary perfusion pressure. ${ }^{24}$ Clearly the time constant of pressure fall describes the overall behaviour of a complicated system, and though relaxation of the ventricle and isolated muscle must have a common mechanism it is unlikely that the time constant measures the rate of a specific process occurring in the ventricle's constituent muscle fibres.

The exponential course of pressure fall can be interpreted in two ways. Once relaxation has started pressure and its rate of change are time dependent. Alternatively, the time constant describes the instantaneous relation between pressure and its rate of change. In the Appendix it is shown that for an exponential model dp/dt is related linearly to pressure; the slope is the negative reciprocal of the time constant, 
and the intercept on the pressure axis is the asymptote. In this sense the rate of relaxation at any time after min dp/dt is "load-dependent", though this may not be strictly analogous to the load dependent component of relaxation in isolated muscle. ${ }^{720} \mathrm{At}$ a given pressure, at any time after $\mathrm{min} \mathrm{dp} / \mathrm{dt}$, when the time constant is long the rate of pressure fall is less than when the time constant is short. It is also shown in the Appendix that $\mathrm{min} \mathrm{dp} / \mathrm{dt}$ is determined by pressure, the time constant, and the asymptote. This is consistent with the known pressure dependence of $\mathrm{min} \mathrm{dp} /$ $\mathrm{dt}^{8}$ and the poor correlation between $\mathrm{min} \mathrm{dp} / \mathrm{dt}$ and the time constant found in our cardiomyopathy patients in whom systolic pressure varied widely between individuals.

At basal heart rate and during pacing the time constant was longer and $\mathrm{min} \mathrm{dp} / \mathrm{dt}$ lower in the cardiomyopathy patients compared with controls, whereas the asymptote was comparable in the two groups. As heart rate increased the time constant became shorter and the asymptote rose towards zero in both groups. Within the cardiomyopathy group there was wide individual variation in the indices of relaxation. As might be expected, $\mathrm{min} \mathrm{dp} / \mathrm{dt}$ correlated with systolic pressure, but the time constant could not be related to systolic pressure, the gradient, or indices of contractility.

At basal heart rate myocardial lactate extraction ratio was similar in the two groups, and only one of the cardiomyopathy patients had an extraction ratio less than $10 \%$. It is unlikely, therefore, that prolongation of the time constant at basal heart rate in the cardiomyopathy patients was the result of ischaemia. During pacing lactate extraction ratios remained high in 13 of the cardiomyopathy patients, but in eight the ratios decreased to low or negative values. Indices of relaxation did not differ between these two subgroups either at basal heart rate or at the highest pacing rate. Thus, there was no evidence that ischaemia was the major cause of abnormal relaxation, or that impaired relaxation predisposes to ischaemia during pacing.

It could be argued that in the eight patients with abnormal lactate extraction the severity of ischaemia was insufficient to affect relaxation. Their lactate extraction ratios, however, were comparable to those measured in this laboratory in patients with coronary artery disease during pacing-induced angina ${ }^{1625}$ in whom prolongation of the time constant is a sensitive index of ischaemia. ${ }^{13}$ In addition, four of these eight patients experienced chest pain during pacing. The apparent lack of effect of ischaemia suggests that the reduced rate of relaxation is the result of the primary myocardial abnormality and that ischaemia has little additional effect. Alternatively, the consequences of ischaemia might depend upon its site. Because of abnormal fibre orientation ${ }^{26}$ and the shape of the sep- tum $^{27}$ the tension generated by some parts of the myocardium makes little contribution to ventricular cavity pressure. By the same argument prolongation of tension decay in ischaemic septal fibres would have little effect upon the time course of intracavity pressure fall in patients with hypertrophic cardiomyopathy.

Beta blocking drugs are known to improve left ventricular diastolic distensibility and reduce enddiastolic pressure in patients with hypertrophic cardiomyopathy. ${ }^{15}$ In this study propranolol, administered at a dose sufficient to reduce contractility and end-diastolic pressure, did not change the time constant. Therefore propranolol did not have a direct effect upon isovolumic relaxation, and it is unlikely that its beneficial action upon diastolic function is caused by acceleration of relaxation.

Acutely, verapamil reduces the duration of isovolumic relaxation and increases the maximum rate of early diastolic filling in patients with hypertrophic cardiomyopathy. ${ }^{5}$ In this study we administered a large dose which caused substantial reductions in systolic pressure and indices of contractility. Min dp/dt decreased in proportion to systolic pressure after the drug, but the time constant and asymptote did not change. Judged by our pressure derived indices isovolumic relaxation is not influenced favourably by verapamil.

Of the 10 patients given propranolol, four had metabolic evidence of ischaemia at the highest pacing rate before the drug. In one of these four lactate extraction increased substantially after the drug, but indices of relaxation did not change. Similarly, verapamil administration increased lactate extraction in two patients at the highest pacing rate, but failed to reduce the time constant. Thus even when they abolish metabolic evidence of myocardial ischaemia neither propranolol nor verapamil increases the rate of isovolumic pressure fall.

From this study it is concluded that both in normal subjects and patients with hypertrophic cardiomyopathy the rate of isovolumic relaxation can be described by a time constant. In most patients with hypertrophic cardiomyopathy the time constant is prolonged, but the severity of abnormal relaxation correlates poorly with other features of the disease. Ischaemia is not the major cause of impaired relaxation. Neither propranolol nor verapamil improves isovolumic relaxation, even when they abolish metabolic evidence of myocardial ischaemia.

\section{Appendix}

The exponential model of pressure fall is

$$
P(t)=a e^{b t}+c
$$


where $\mathrm{P}(\mathrm{t})=$ pressure at time $\mathrm{t}$

$(\mathrm{t})=$ time after $\min \mathrm{dp} / \mathrm{dt}$

(c) $=$ the asymptote

(a) $=\mathrm{P}(\mathrm{o})-\mathrm{c}($ where $\mathrm{P}(\mathrm{o})=$ pressure at the time of $\mathrm{min} \mathrm{dp} / \mathrm{dt}$ )

the time constant, $T=-\frac{1}{b}$

by differentiation equation (1) becomes

$\mathrm{dp} / \mathrm{dt}(\mathrm{t})=a e^{\mathrm{bt}} \cdot \mathrm{b}$

by substitution in equation (1)

$P(t)-c=a e^{b t}$

Dividing (2) by (3)

$$
\frac{\mathrm{dp} / \mathrm{dt}}{\mathrm{P}(\mathrm{t})-\mathrm{c}}(\mathrm{t})=\mathrm{b}
$$

Thus the rate of change of pressure is related to pressure by the slope $b$ (of which the time constant is the negative reciprocal)

When $P(t)=c d p / d t(t)=0$.

Thus the asymptote is the intercept on the pressure axis.

By definition $\mathrm{min} \mathrm{dp} / \mathrm{dt}$ occurs at time 0 .

From equation (2)

$\min \mathrm{dp} / \mathrm{dt}=\mathrm{a} . \mathrm{b}$.

and by substitution

$\min \mathrm{dp} / \mathrm{dt}=\frac{\mathrm{P}_{(0)}-\mathrm{c}}{-\mathrm{T}}$

\section{References}

1 Swanton RH, Brooksby IAB, Jenkins BS, Webb-Peploe MM. Hemodynamic studies of beta-blockade in patients with hypertrophic obstructive cardiomyopathy. Eur $\mathcal{f}$ Cardiol 1977; 5/4: 327-41.

2 Sanderson JE, Gibson DG, Brown DJ, Goodwin JF. Left ventricular filling in hypertrophic cardiomyopathy: an angiographic study. Br Heart f 1977; 39: 661-70.

3 St John Sutton MG, Tajik AJ, Gibson DG, Brown DJ, Seward JB, Guiliani ER. Echocardiographic assessment of left ventricular filling and septal and posterior wall dynamics in idiopathic hypertrophic subaortic stenosis. Circulation 1978; 57: 512-20.

4 St John Sutton MG, Tajik AJ, Smith HC, Ritman EL. Angina in idiopathic hypertrophic subaortic stenosis. Circulation 1980; 61: 561-8.

5 Hanrath P, Mathey DG, Kremer P, Sonntag F, Bleifeld W. Effect of verapamil on left ventricular isovolumic relaxation time and regional left ventricular filling in hypertrophic cardiomyopathy. Am $\mathcal{F}$ Cardiol 1980; 45: 1258-64.

6 Webb-Peploe MM, Croxson RS, Oakley CM, Goodwin JF. Cardioselective beta-adrenergic blockade in hypertrophic obstructive cardiomyopathy. Postgrad Med $\mathcal{F}$ $1971 ; 47$, suppl: 93-6.
7 Brutseart DL, Housmans PR, Goethals MA. Dual control of relaxation: its role in the ventricular function of the mammalian heart. Circ Res 1980; 47: 637-52.

8 Weisfeldt ML, Scully HE, Frederiksen J, et al. Hemodynamic determinants of maximum negative $\mathrm{dp} / \mathrm{dt}$ and periods of diastole. Am $\mathcal{Y}$ Physiol 1974; 227: 613-21.

9 Weiss JL, Frederiksen JW, Weisfeldt ML. Hemodynamic determinants of the time-course of fall in canine left ventricular pressure. $\mathcal{F}$ Clin Invest 1976; 58: $751-60$.

10 Karliner JS, LeWinter MM, Mahler F, Engler R, O'Rourke RA. Pharmacologic and hemodynamic influences on the rate of isovolumic left ventricular relaxation in the normal conscious dog. $\mathcal{F}$ Clin Invest 1977; 60: $511-21$.

11 Weisfeldt ML, Frederiksen JW, Yin FCP, Weiss JL. Evidence of incomplete left ventricular relaxation in the dog. Prediction from the time constant for isovolumic pressure fall. $\mathcal{F}$ Clin Invest 1978; 62: 1296-302.

12 Thompson DS, Waldron CB, Juul SM, Coltart DJ, Jenkins BS, Webb-Peploe MM. Comparison of two methods of estimating time constant of left ventricular relaxation (abstract). Br Heart f 1981; 45: 348P.

13 Thompson DS, Waldron CB, Juul SM, et al. Analysis of left ventricular pressure during isovolumic relaxation in coronary artery disease. Circulation 1982; 65: 690-7.

14 Thompson DS, Waldron CB, Coltart DJ, Jenkins BS, Webb-Peploe MM. Estimation of time constant of left ventricular relaxation. $\mathrm{Br}$ Heart $\mathcal{f}$ 1983; 49:250-8.

15 Thompson DS, Naqvi N, Juul SM, et al. Effects of propranolol on myocardial oxygen consumption, substrate extraction, and haemodynamics in hypertrophic obstructive cardiomyopathy. Br Heart $f$ 1980; 44: 488-98.

16 Thompson DS, Naqvi N, Juul SM, Coltart DJ, Jenkins BS, Webb-Peploe MM. Haemodynamic and metabolic effects of atenolol in patients with angina pectoris. $\mathrm{Br}$ Heart f 1980; 43: 668-79.

17 Brooksby IAB, Swanton RH, Jenkins BS, Webb-Peploe MM. Long-sheath technique for introduction of catheter tip micromanometer or endomyocardial bioptome into left or right heart. $\mathrm{Br}$ Heart $\mathcal{F}$ 1974; 36: 908-12.

18 Grossman W, Brooks H, Meister S, Sherman H, Dexter L. New technique for determining instantaneous myocardial force-velocity relations in the intact heart. Circ Res 1971; 28: 290-7.

19 Hohorst HJ, Kreutz FH, Bücher T. Uber Metabolitgehalte und Metabolit-Konzentrationen in der Leber der Ratte. Biochemische Zeitschrift 1959; 332: $18-$ 46.

20 Brutsaert DL, De Clerck NM, Goethals MA, Housmans N PR. Relaxation of ventricular cardiac muscle. $\mathcal{F}$ Physiol (Lond) 1978; 283: 469-80.

21 Wiegner AW, Bing OHL. Isometric relaxation of rat myocardium at end-systolic fiber length. Circ Res 1978; 43: 865-9.

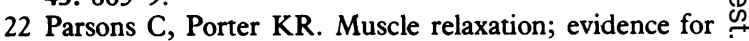
an intrafibrillar restoring force in vertebrate striated 0 muscle. Science 1966; 153: 426-7.

23 Rushmer RF, Crystal DK, Wagner C. The functional $\mathbb{\mathbb { D }}$ anatomy of ventricular contraction. Circ Res 1953; 1: $162-70$.

24 Hoffman JIE. Determinants and prediction of trans-

क .

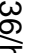


mural myocardial perfusion. Circulation 1978; 58: 38191.

25 Naqvi N, Thompson DS, Juul SM, Jenkins BS, WebbPeploe MM, Coltart DJ. Stimulation of myocardial lactate extraction by oxifenicine. Eur Heart $f$ 1980; 1: 45963.

26 Bulkey BH, Weisfeldt MR, Hutchins GM. Isometric cardiac contraction. A possible cause of the disorganized myocardial pattern of idiopathic hypertrophic subaortic stenosis. N Engl f Med 1977; 296: 135-9.
27 Hutchins GM, Bulkey BH. Catenoid shape of the interventricular septum: possible cause of idiopathic hypertrophic subaortic stenosis. Circulation 1978; 58: 392-7.

Requests for reprints to Dr D S Thompson, Department of Cardiology, St Thomas's Hospital, London SE1 7EH. 